\title{
University of Pittsburgh Cancer Institute
}

National Cancer Institute

\section{Source}

National Cancer Institute. University of Pittsburgh Cancer Institute. NCI Thesaurus. Code C39555.

The mission of the University of Pittsburgh Cancer Institute is to decrease the mortality and morbidity from cancer across the nation, and especially in western Pennsylvania, through integrated programs in basic, clinical, translational, and population and cancer control research. The Institute maintains a comprehensive approach to understanding and defeating cancer. It was named an $\mathrm{NCl}$-designated comprehensive cancer center in 1989. 